\title{
Cranial Ultrasonographic Findings in Preterm Infants at Tanta Neonatal Intensive Care Unit (NICU)
}

\author{
DALIA M. EL-KAMAH, M.Sc.; RASHA M.G. EL-SHAFIEY, M.D.; MOHAMED A. EL-TOMY, M.D. and \\ MOHAMED A. ROWISHA, M.D.
}

The Department of Pediatric, Faculty of Medicine, Tanta University, Tanta, Egypt

\begin{abstract}
Background: Premature neonates are at risk for brain injury both hemorrhagic and ischemic injury. Intracranial hemorrhage is the most common abnormal cranial finding followed by PVL and hydrocephalus. Considering that most of the brain lesions are clinically silent during the neonatal period, routine cranial ultrasonography screening may be needed to detect a variety of brain lesions in the preterm infants.
\end{abstract}

Aim: The aim was to detect cranial ultrasonographic findings in preterm infants for initiation of appropriate, protective and therapeutic measures.

Methods and Material: This study was carried out on all preterms infants that were admitted in the NICU of Pediatric Department at Tanta University Hospital during the study period over one year using cranial US in the first 3 days of life and on $7^{\text {th }}, 14^{\text {th }}$ and $21^{\text {st }}$ days of life and after any clinical intercurrent events through anterior, posterior and mastoid fontanelle with a single operator, who was unaware of any clinical data of the studied preterms.

Results: Most of the preterms were asymptomatic and hypotonia was the main symptom among symptomatic preterms. ICH was the most common abnormal CUS finding followed by PVL and hydrocephalus. Hydrocephalus was the main complication of ICH cases. Regarding the grading of $\mathrm{ICH}$, grade III represented the predominant grade. In the studied preterms, those with gestational age $\leq 32$ weeks, birth weight $<1.5 \mathrm{Kg}, \mathrm{Hb} \leq 10 \mathrm{gm}$.dL, and mean $\mathrm{PCO}_{2}>45$ were more likely to have abnormal findings on cranial US examination.

Conclusions: Cranial US may be recommended as a routine examination in every preterm infant as most of preterms with abnormal cranial US findings are asymptomatic. The incidence of abnormal CUS findings increases with decreasing gestational age, birth weight, APGAR score, $\mathrm{Hb}, \mathrm{pH}$ and $\mathrm{HCO}_{3}$ and with increasing $\mathrm{HR}, \mathrm{RR}, \mathrm{CRP}$, mean $\mathrm{PCO}_{2}$ and length of stay.

Key Words: Cranial - US - Preterm - Hydrocephalus - PVL.

Correspondence to: Dr. Dalia M. El-Kamah, The Department of Pediatric, Faculty of Medicine, Tanta University

\section{Introduction}

PRETERM birth is defined as childbirth occurring at less than 37 completed weeks or 259 days of gestation. It is a major determinant of neonatal mortality and morbidity and has long term adverse consequences for health [1]

Morbidity associated with prematurity are enormous and include respiratory, cardiovascular, hematological, neurological, nutritional, feeding difficulties and infection [2].

Children who are born prematurely have higher rates of cerebral palsy, sensory deficits, learning disabilities and respiratory illnesses compared with children born at term. The morbidity associated with preterm birth often extends to later life, resulting in enormous physical, psychological and economic costs [1]

World Health Organization [1] estimates of global rates of preterm births indicate that of the 135 million lives birth worldwide in 2010, about 15 million babies were born too early, representing a preterm birth rate of $11.1 \%$, over $60 \%$ of preterm birth occurred in Sub Saharan Africa and South Asia where 9.1 million births (12.8\%) annually are estimated to be preterm [3].

Deaths within the first seven days of life that are not related to congenital malformation, $28 \%$ of them are due to preterm births [4].

In Egypt, prematurity was the main cause of neonatal mortality (39\%) [5]

According to UNICEF, $12 \%$ of live neonates in Egypt were low birth weight, and it was estimated that about one third of such infants are preterms [6] 
Brain is vulnerable to many destructive lesions in preterm infants which include white matter lesions, grey matter lesions, Periventricular Leukomalacia (PVL), Germinal Matrix, Intraventricular Hemorrhage (GM-IVH) and behavioral and attention problems [7].

Brain ultrasound is well-established method for both initial evaluation and follow-up for preterm babies [8].

Considering that the most of the brain lesions are clinically subtle or silent during the neonatal period, cranial ultrasound screening may play a role in detecting at risk babies of impaired neurodevelopment later in childhood and identifying the most significant perinatal risk factors associated with brain lesions in order to target the potential need for cranial ultrasound at birth [9].

\section{Aim and objectives:}

The aim of this work was to detect cranial ultrasonographic findings in preterm infants for initiation of appropriate protective and therapeutic measures.

\section{Methods and Material}

This study was carried out on all preterm infants that were admitted in NICU of Pediatric Department at Tanta University Hospital during the study period over one year from November 2015 to November 2016. Inclusion criteria included Preterm infants born at less than 37 weeks gestational age. Exclusion criteria included preterm with congenital heart diseases and any other heart disease which may alter cerebral flow velocities, preterm with congenital STORCH infection, preterm with abnormal neurological symptoms and sign and preterm with significant dysmorphic features.

All studied preterm were subjected to full history taking with special emphasis on gestational age, postnatal age, sex, mode of delivery, birth weight, premature rapture of membranes, Antenatal medications (i.e. steroids, antibiotics, $\mathrm{Mg}$ sulphate), twin pregnancy, Initiator of preterm delivery (pregnancy induced hypertension, preterm labour or others) and APGAR score at 1 and 5 minutes.

Thorough clinical examination including neurological examination on admission, measurement of head circumference and mean blood pressure in the first 7 days of life was done. Complete blood count, serum C-reactive protein, serum electrolytes ( $\mathrm{Na}, \mathrm{K}, \mathrm{Ca}, \mathrm{Mg}$ ) and capillary blood gases especially mean $\mathrm{PCO} 2$ in the first 7 days of life were evaluated.
Transfontanellar cranial ultrasound evaluation was done in the first 3 days of life and on $7^{\text {th }}, 14^{\text {th }}$ and 21 st days of life after any clinical intercurrent events, the CUS examination was done by a single operator, he was unaware of any clinical data of the studied preterms.

Statistical presentation and analysis was conducted by SPSS V. 24. $p$-value $<0.05$ was considered significant.

\section{Results}

The 40 pretems in this study, included: Extreme preterm one case $(2.5 \%)$, very preterm $14(35 \%)$ and late preterm $25(62.5 \%) .21$ cases $(52.50 \%)$ were male. 29 cases $(72.50 \%)$ delivered by CS. the mean gestational age was $(31.550 \pm 2.230)$, mean birth weight was $(1.624 \pm 0.515)$ mean SBP was (79.059 \pm 7.053$)$, mean DBP was $(47.588 \pm 9.430)$, mean hemoglobin was $(11.440 \pm 1.657)$, mean Creactive protein was $(22.545 \pm 16.296)$, mean $\mathrm{PH}$ was (7.330 \pm 0.095$)$, mean $\mathrm{PaCO}_{2}(44.225 \pm 9.934)$, mean $\mathrm{HCO}_{3}(26.125 \pm 3.791)$, the mean length of stay was $(33.025 \pm 15.994), 3$ cases $(82.50 \%)$ discharged and 7 cases $(17.50 \%)$ died (Table 1$)$. There was no significant difference regarding CUS findings (normal and abnormal) on comparing the 4 times of assessment ( 3 rd, ${ }^{\text {th, }} 14$ th, 21 st) also regarding the types of abnormal CUS findings Fig. (1), but we found that intracranial hemorrhage was the most common abnormal cranial US finding in the studied preterms followed by periventricular leukomalacia and hydrocephalus Fig. (2).

Table (1): Characterstics of studied preterms.

\begin{tabular}{|c|c|c|}
\hline & $\mathrm{N}$ & $\%$ \\
\hline \multicolumn{3}{|l|}{ Gestational age: } \\
\hline Extreme preterm & 1 & 2.50 \\
\hline Very preterm & 14 & 35.00 \\
\hline Late preterm & 25 & 62.50 \\
\hline \multicolumn{3}{|l|}{ Sex: } \\
\hline Male & 21 & 52.50 \\
\hline Female & 19 & 47.50 \\
\hline \multicolumn{3}{|l|}{ Mode of delivery: } \\
\hline CS & 29 & 72.50 \\
\hline \multirow[t]{2}{*}{ NVD } & 11 & 27.50 \\
\hline & Range & Mean \pm SD \\
\hline Mean SBP (mmHg) & $70-100$ & $79.059 \pm 7.053$ \\
\hline Mean DBP $(\mathrm{mmHg})$ & $80-35.7$ & $47.588 \pm 9.430$ \\
\hline Length of stay (days) & $14-65$ & $33.025 \pm 15.994$ \\
\hline $\mathrm{Hb}(\mathrm{gm} / \mathrm{dL})$ & $15-7$ & $11.440 \pm 1.657$ \\
\hline $\mathrm{CRP}(\mathrm{mg} / \mathrm{L})$ & $48-6$ & $22.545 \pm 16.296$ \\
\hline Mean $\mathrm{PaCO}_{2}(\mathrm{mmHg})$ & $60-18$ & $44.225 \pm 9.934$ \\
\hline $\mathrm{HCO}_{3}(\mathrm{mEq} / \mathrm{L})$ & $32-18$ & $26.125 \pm 3.791$ \\
\hline $\mathrm{pH}$ & $7.45-7.14$ & $7.330 \pm 0.095$ \\
\hline
\end{tabular}




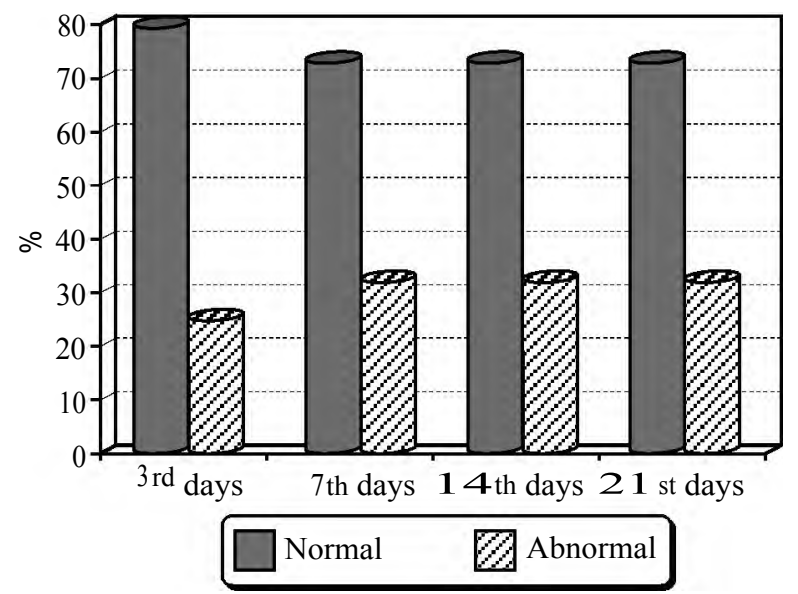

Fig. (1): Comparison between the cranial US findings in the 4 days of assessment.

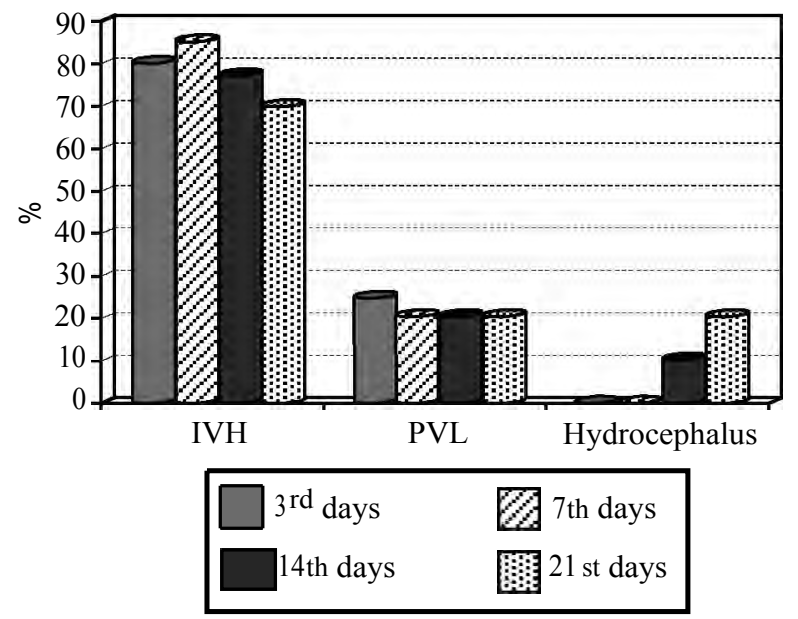

Fig. (2): Abnormal CUS findings in the studied preterms.
There was a significant increase in detection of ICH with progressing timing of assessment and with increasing grading and severity where grade III represented the predominant grade Fig. (3).

All the studied preterms were asymptomatic for neurological affection on enrollment, however only few cases developed abnormal symptoms on follow-up where the hypotonia was the main abnormal neurological finding among the symptomatic preterms Fig. (4).

On comparing preterms with normal and abnormal CUS findings, gestational age, birth weight, length, APGAR score at 1 and 5 minutes, $\mathrm{Hb}$ and $\mathrm{pH}$ were significantly lower in those with abnormal CUS compared with those with normal CUS which means that lowering of these factors are associated with increasing the incidence of abnormal cranial US findings especially ICH (Table 2).

On comparing preterms with normal and abnormal CUS, HR, RR, CRP, mean $\mathrm{PCO} 2, \mathrm{HCO}_{3}$ and length of stay were significantly higher in preterms with abnormal CUS compared to those with normal CUS which means that increasing of these factors are associated with increasing the incidence of abnormal CUS findings (Table 2).

In the studied preterms, those with gestational age $\leq 32$, birth weight $\leq 1.5, \mathrm{Hb} \leq 10$ and mean $\mathrm{PCO}_{2}>45$ were more likely to have abnormal findings on cranial US examination (Table 3 ).

Table (2): Comparison of characteristics and findings in the studied preterms between those with normal and abnormal CUS.

\begin{tabular}{lllll}
\hline & \multicolumn{3}{c}{ US } & \multicolumn{2}{c}{$t$-test or chi-square } \\
\cline { 2 - 5 } & \multicolumn{1}{c}{$\begin{array}{c}\text { Normal } \\
\text { Mean } \pm \text { SD }\end{array}$} & $\begin{array}{c}\text { Abnormal } \\
\text { Mean } \pm \text { SD }\end{array}$ & $\begin{array}{c}t \text { or } \\
\chi^{2}\end{array}$ & $\begin{array}{c}p \text { - } \\
\text { value }\end{array}$ \\
\hline - Gestational age & $32.500 \pm 1.856$ & $29.333 \pm 1.231$ & 5.403 & $<0.001^{*}$ \\
- Birth weight (Kg) & $1.820 \pm 0.475$ & $1.167 \pm 0.242$ & 4.491 & $<0.001^{*}$ \\
- Length (cm) & $51.732 \pm 0.967$ & $49.875 \pm 1.509$ & 4.678 & $<0.001^{*}$ \\
- APGAR 1 (1min) & $4.036 \pm 1.795$ & $1.917 \pm 1.505$ & 3.579 & $0.001^{*}$ \\
- APGAR 2 (5min) & $7.643 \pm 1.026$ & $4.833 \pm 2.855$ & 4.619 & $<0.001^{*}$ \\
- HR (beat/min) & $160.000 \pm 0.000$ & $172.500 \pm 5.436$ & -12.388 & $<0.001^{*}$ \\
- RR (cycle/min) & $45.000 \pm 0.000$ & $65.833 \pm 4.687$ & -23.943 & $<0.001^{*}$ \\
- Mean PCO2 in first 7 days of & $39.029 \pm 3.735$ & $49.425 \pm 6.839$ & -6.222 & $<0.001^{*}$ \\
life (mmHg) & & & & \\
- pH & $7.374 \pm 0.045$ & $7.225 \pm 0.100$ & 6.543 & $<0.001^{*}$ \\
- HCO (mEq/L) & $28.333 \pm 4.163$ & $25.179 \pm 3.255$ & 2.581 & $0.014^{*}$ \\
- Hb (gm/dl) & $11.950 \pm 1.331$ & $10.250 \pm 1.784$ & 3.337 & $0.002^{*}$ \\
- CRP (mg/l) & $14.286 \pm 10.978$ & $37.000 \pm 13.974$ & -5.176 & $<0.001 *$ \\
- Length f stay (days) & $25.714 \pm 10.270$ & $50.083 \pm 13.951$ & -6.164 & $<0.001^{*}$ \\
\hline
\end{tabular}

* Significant at $(p$-value $<0.05)$.

* Highly significant at $(p$-value $<0.001)$. 
Table (3): Odds ratio and some parameters in the study.

\begin{tabular}{|c|c|c|c|c|c|c|}
\hline & \multicolumn{4}{|c|}{ US } & \multirow{3}{*}{$\begin{array}{l}\text { Odds } \\
\text { ratio }\end{array}$} & \multirow{3}{*}{$\begin{array}{c}p- \\
\text { value }\end{array}$} \\
\hline & \multicolumn{2}{|c|}{ Normal } & \multicolumn{2}{|c|}{ Abnormal } & & \\
\hline & $\mathrm{N}$ & $\%$ & $\mathrm{~N}$ & $\%$ & & \\
\hline \multicolumn{7}{|c|}{ Gestational age: } \\
\hline$<32$ & 13 & 46.43 & 12 & 100.00 & 0.035 & $0.024 *$ \\
\hline$>32$ & 15 & 53.57 & 0 & 0.00 & & \\
\hline \multicolumn{7}{|c|}{ Birth weight $(\mathrm{Kg})$ : } \\
\hline$\leq 1.5$ & 9 & 32.14 & 10 & 83.33 & 0.094 & $0.007 *$ \\
\hline$>1.5$ & 19 & 67.86 & 2 & 16.67 & & \\
\hline \multicolumn{7}{|c|}{$H b(g m / d L):$} \\
\hline$\leq 10$ & 2 & 7.14 & 7 & 58.33 & 0.055 & $0.002 *$ \\
\hline$>10$ & 26 & 92.86 & 5 & 41.67 & & \\
\hline \multicolumn{7}{|c|}{ Mean PCO2 in first 7 days of life $(\mathrm{mmHg})$ : } \\
\hline$<45$ & 27 & 96.43 & 2 & 16.67 & 135.000 & $<0.001 *$ \\
\hline$>45$ & 1 & 3.57 & 10 & 83.33 & & \\
\hline
\end{tabular}

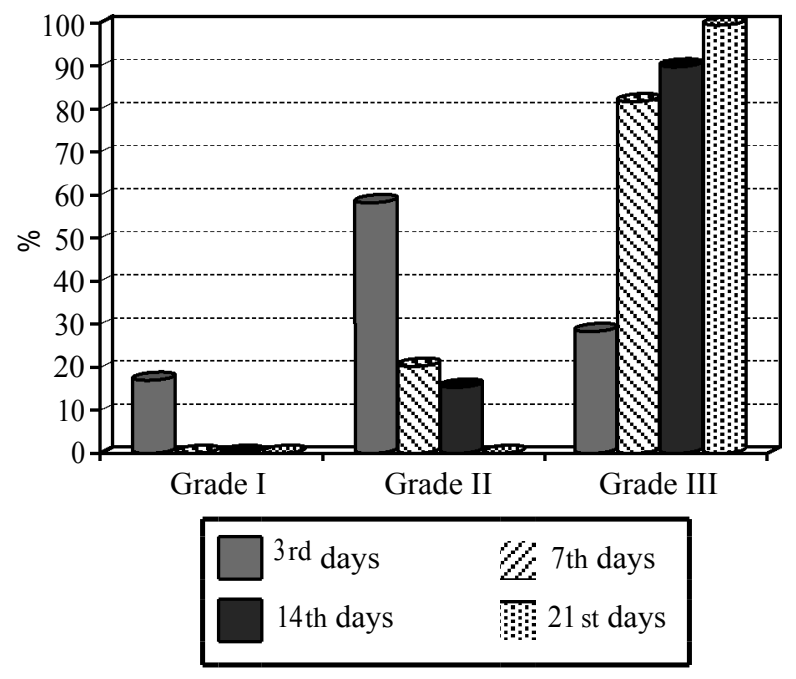

Fig. (3): Comparison between the different grades of ICH during the 4 days of assessment (classified on the Papile et al., and Volpe et al., degrees).

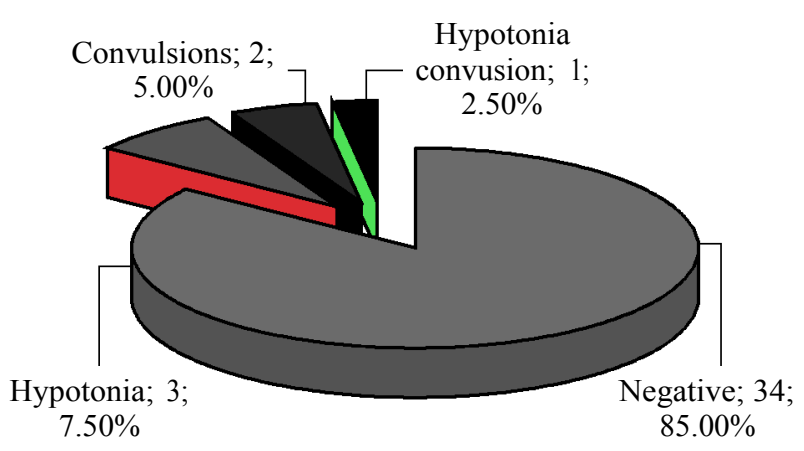

Fig. (4): Neurological examination of the studied preterms.

\section{Discussion}

Neonates born prematurely are at risk of brain injury, although advances in neonatal care have greatly improved the survival and outcome of these vulnerable patients, brain injury still remains a major concern. Transfontanelle cranial sonography is an important investigation for evaluation of the neurological status of neonates and infants, whether symptomatic or asymptomatic. The posterior fontanelle and mastoid fontanelle imaging techniques are useful for the detection of posterior fossa abnormalities and small IVH with normal-sized ventricles [10].

This study included 40 preterm neonates. All the preterm neonates underwent transfontanellar cranial ultrasound evaluation in the first 3 days of life and on 7 th, 14th and $21^{\text {st }}$ days of life and after any clinical intercurrent event. And were subjected to history taking, clinical examination, laboratory and radiological assessment.

Our results agree with Vollmer et al., [11] who demonstrated that the increased risk of certain intracranial lesions, especially hemorrhagic lesions were particularly associated with birth at very low gestational age, whereas PVL was distributed between 24 and 32 weeks of gestation. It also agree with Kalyani et al., [12] and with De Vries et al., [13] where CUS lesions were detected in the majority of infants $(92 \%)$ born $<32$ weeks of gestation.

In our study, on comparing preterms with normal and abnormal CUS, birth weight was significantly lower in those with abnormal CUS compared with those with normal CUS with $(p=<0.001)$, where 10 cases $(83.33 \%)$ of preterms with abnormal CUS findings weighing $<1.5 \mathrm{Kg}$. In agree with our results Debbarma et al., (2016) [14] showed that there was an association between increment of birth weight and declining in the incidence of ICH, 
especially significant in the infants below $1 \mathrm{~kg}$, it also agree with Bhat et al., [15], but in a study done by Islam et al., [16] there was no significant difference as regard birth weight in both normal and abnormal CUS findings and also gestational age and this against our results which may refer to the difference in neonatal care between each NICU that would allow survival of very preterm infants with low birth weight.

In our study there was a significant difference as regard APGAR score where we found that preterms with abnormal CUS findings had lower APGAR score at 1 and $5 \mathrm{~min}$ which is in agreement with Brezan et al., [17] study who found that there was an inverse relationship between the APGAR score at 1 and 5 minutes and both the incidence and severity of $\mathrm{ICH}$ in the study groups.

It disagree with Giannakopoulos et al., [18] who showed that infants with a gestational age of less than 34 weeks, who were exposed to $\mathrm{PaCO} 2$ values of less than $25 \mathrm{mmHg}$ during the first 3 days after birth, demonstrated a significantly higher incidence of PVL compared with infants with lowest $\mathrm{PaCO} 2$ values greater than $25 \mathrm{mmHg}(30.76 \%$ vs $5.8 \%$, respectively).

In our study there was a significant increase in the incidence of abnormal CUS findings among preterms with low Hb level with $(p=0.002)$, this is agreeing with Horsch S et al., [19] study which showed that abnormal brain lesions were associated with low Hb level.

In this study there was a significant increase in the incidence of abnormal CUS findings with high CRP level with $(p=<0.001)$ which is against Horsch $\mathrm{S}$ et al., [19] study that showed no significant difference as regard CRP between the studied preterms (normal and abnormal CUS findings).

In our study all the studied preterms were asymptomatic for neurological affection on enrollment, however, on follow-up, 3 preterms developed hypotonia, 2 preterms developed convulsions, and one of them developed both hypotonia accompanied by convulsion, while $85 \%$ remained asymptomatic. Out of 12 preterms with abnormal CUS, 6 (50\%) remained asymptomatic. All preterms who developed neurological manifestations showed abnormal findings on CUS examinations.

This is agree with Brezan et al., [17] and the study of Bhat et al., [15] which demonstrated that a significant number of infants with abnormal CUS findings (the 20 infants detected with grade I-II
ICH and 4 out of 7 with grade III-IV ICH or PVL) were clinically silent. But in contrast to our results the study of Harris et al., [20] which showed that all the infants with IVH and those with PVL in their study had either symptoms or perinatal risk factors for brain injury.

We found that the commonest abnormal CUS findings in the preterms was ICH followed by PVL and hydrocephalus, where hydrocephalus was a complication of intraventricular hemorrhage, this agree with Sajjadian et al., [21] study which showed that IVH is the most common abnormal brain lesion and attendant complications (hydrocephalus) but unlike our study most of the cases of IVH in their study were grade I IVH which may refer to that the CUS is an operator dependent technique and this grade may be missed in some cases especially that most of preterms with grade I are usually asymptomatic.

Our study results agree with the study of Kumar et al., [22] who showed that IVH was the commonest abnormalities among preterms, also he showed that hydrocephalus was a complication of IVH. Also our results agree with Brezan et al., [17] who demonstrated that almost one quarter of cases were diagnosed with one type of $\mathrm{ICH}$, but in disagree with our results the subependimal hemorrhages represented the majority of cases $(40 \%)$, also in agree with our results he found that post hemorrhagic hydrocephalus was only observed in some of the subjects with grade III and IV.

However, we found that there was a significant difference in grading of ICH during the times of assessment, so according to our study earlier scanning permits use of the information in clinical care of the infant while later scanning permits sequential evaluation of the progression of an abnormality demonstrated early in the neonatal period. Grading of ICH in our study classified cases on the Papile and Volpe 4 degrees' scale. This agree with Ment et al., [23] who showed that IVH could be detected early where approximately $65 \%$ of IVH cases were detected within the first week when regular US was performed at predefined times (1-5 days, 1014 days, 28 days, and term) and also found that with timing of assessment more severe grades of IVH had been detected.

There are several limitations of our study, the most important being the lack of data on the late outcome of prematurity (follow-up until at least 6 years of age), along with the relatively small number of cases. 


\section{Conclusions:}

From this study, we can conclude cranial US may be recommended as a routine examination in every preterm infant as most of preterms with abnormal cranial US findings are asymptomatic. The incidence of abnormal CUS findings increases with decreasing gestational age, birth weight, APGAR score, $\mathrm{Hb}, \mathrm{pH}$ and $\mathrm{HCO}_{3}$ and with increasing $\mathrm{HR}, \mathrm{RR}, \mathrm{CRP}$, mean $\mathrm{PCO} 2$ and length of stay.

\section{Acknowledgments:}

This research was carried out without funding.

\section{Conflicts of interest:}

No conflicts of interest declared.

\section{Authors' contributions:}

All authors had equal role in design, work, statistical analysis and manuscript writing.

\section{References}

1- PERINATAL W.: Neonatal mortality for the year 2000: Country, regional and global estimates. Geneva: World Health Organization; 2006.

2- CLOHERTY J.P., EICHENWALD E.C. and STARK A.R.: Manual of neonatal care: Lippincott Williams \& Wilkins; 2008.

3- BLENCOWE H., COUSENS S., OESTERGAARD M.Z., CHOU D., MOLLER A.B., NARWAL R., et al.: National, regional, and worldwide estimates of preterm birth rates in the year 2010 with time trends since 1990 for selected countries: A systematic analysis and implications. The Lancet; 379 (9832): 2162-72, 2012.

4- GOLDENBERG R.L., CULHANE J.F., IAMS J.D. and ROMERO R.: Epidemiology and causes of preterm birth. The lancet; 371 (9606): 75-84, 2008.

5- CAMPBELL O., GIPSON R., EL MOHANDES A., ISSA A.H., MATTA N., MANSOUR E., et al.: The Egypt national perinatal/neonatal mortality study 2000 . Journal of Perinatology; 24 (5): 284-9, 2004.

6- AHMED A.H.: Breastfeeding preterm infants: An educational program to support mothers of preterm infants in Cairo, Egypt. Pediatric Nursing; 34 (2): 125, 2008.

7- FAWKE J.: Editor Neurological outcomes following preterm birth. Seminars in fetal and neonatal medicine; Elsevier, 2007.

8- VEYRAC C., COUTURE A., SAGUINTAAH M. and BAUD C.: Brain ultrasonography in the premature infant. Pediatric radiology; 36 (7): 626-35, 2006.

9- SHAPIRO-MENDOZA C.K. and LACKRITZ E.M.: Editors. Epidemiology of late and moderate preterm birth. Seminars in Fetal and Neonatal Medicine; Elsevier, 2012.

10- CORREA F., ENRIQUEZ G., ROSSELLO J., LUCAYA J., PIQUERAS J., ASO C., et al.: Posterior fontanelle sonography: An acoustic window into the neonatal brain. A.J.N.R. American Journal of Neuroradiology; 25 (7): 1274-82, 2004.
11- VOLLMER B., ROTH S., BAUDIN J., STEWART A.L., NEVILLE B.G. and WYATT J.S.: Predictors of longterm outcome in very preterm infants: Gestational age versus neonatal cranial ultrasound. Pediatrics; 112 (5): 1108-14, 2003.

12- KALYANI R.: Cranial Ultrasonography in Preterm and Term Neonates. Int. J. Res. Health Sci. [Internet]; 2 (1): 229-35, 2014

13- De VRIES L.S., VAN HAASTERT I.-L.C., RADEMAKER K.J., KOOPMAN C. and GROENENDAAL F.: Ultrasound abnormalities preceding cerebral palsy in high-risk preterm infants. The Journal of Pediatrics; 144 (6): 81520, 2004.

14- DEBBARMA R., De A. and DEBBARMA S.: Incidence of intracranial haemorrhage in low-birth weight infants and its outcome: A hospital based prospective study. International Journal of Research in Medical Sciences; 4 (10): 4279-85, 2016.

15-BHAT V., KARAM M., SASLOW J., TAYLOR H., PYON K., KEMBLE N., et al.: Utility of performing routine head ultrasounds in preterm infants with gestational age 30-34 weeks. The Journal of Maternal-Fetal \& Neonatal Medicine; 25 (2): 116-9, 2012.

16- ISLAM M.M.Z., ISLAM M.A., HOSSAIN M.M. and KHAN N.Z.: Cranial Ultrasound in Preterm Neonates: Screening of at Risk Infants for Long Term Neurodevelopmental Impairments. Journal of Enam Medical College 6 (1): 28-32, 2016.

17- BREZAN F., RITIVOIU M., DRAGAN A., CODREANU I., RADUCANU D., FEIER D., et al.: Preterm screening by transfontanelar ultrasound-results of a 5 years cohort study. Medical Ultrasonography; 14 (3): 204, 2012.

18- GIANNAKOPOULOU C., KORAKAKI E., MANOURA A., BIKOUVARAKIS S., PAPAGEORGIOU M., GOURGIOTIS D., et al.: Significance of hypocarbia in the development of periventricular leukomalacia in preterm infants. Pediatrics international; 46 (3): 268-73, 2004.

19- HORSCH S., MUENTJES C., FRANZ A. and ROLL C.: Ultrasound diagnosis of brain atrophy is related to neurodevelopmental outcome in preterm infants. Acta Paediatrica; 94 (12): 1815-21, 2005.

20- HARRIS N.J.N., PALACIO D., GINZEL A., RICHARDSON C.J. and SWISCHUK L.: Are routine cranial ultrasounds necessary in premature infants greater than 30 weeks gestation? American Journal of Perinatology; 24 (01): 017-21, 2007.

21- SAJJADIAN N., FAKHRAI H. and JAHADI R.: Incidence of intraventricular hemorrhage and post hemorrhagic hydrocephalus in preterm infants. Acta Medica Iranica; (4): 260-2, 2010.

22- KUMAR N., SINGH M.K., GUPTA A., GILL J., SINGH S.K. and GUPTA V.: Role of cranial ultrasound for diagnosis of intracranial abnormalities in newborns. Pediatric Review: International Journal of Pediatric Research; 3 (04), 2016.

23- MENT L., BADA H., BARNES P., GRANT P., HIRTZ D., PAPILE L., et al.: Practice parameter: Neuroimaging of the neonate Report of the Quality Standards Subcommittee of the American Academy of Neurology and the Practice Committee of the Child Neurology Society. Neurology; 58 (12): 1726-38, 2002. 


\section{معلد الإعاقات فى المخ بالموجات فوق الصوتية فى الخدج

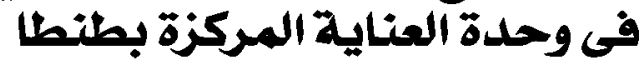

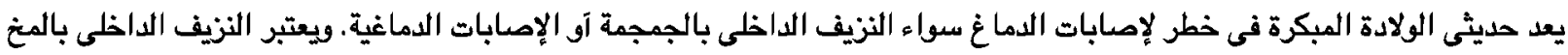

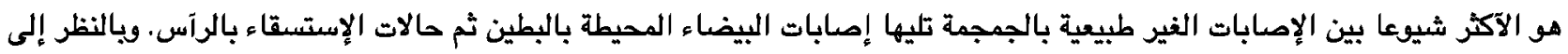

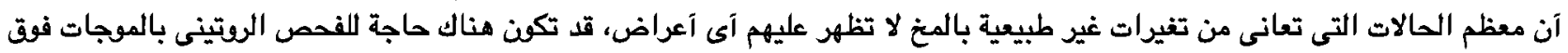

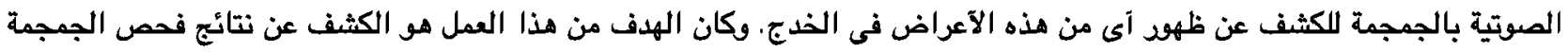

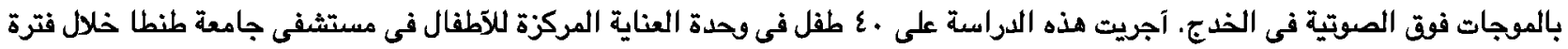

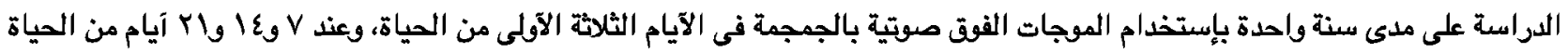

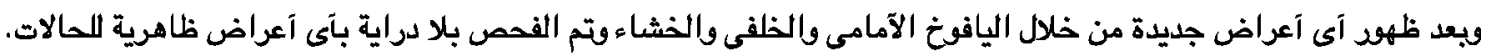

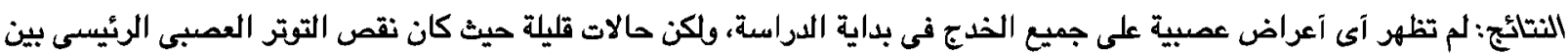

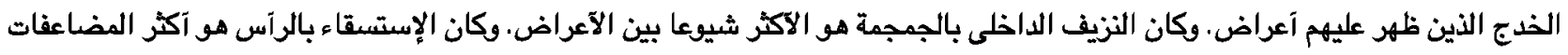

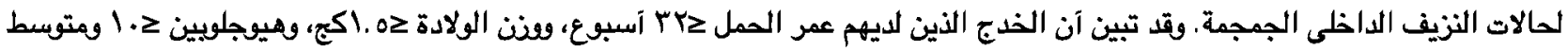

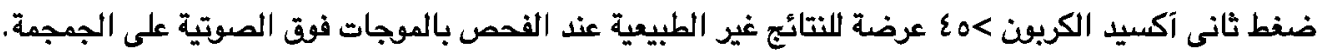

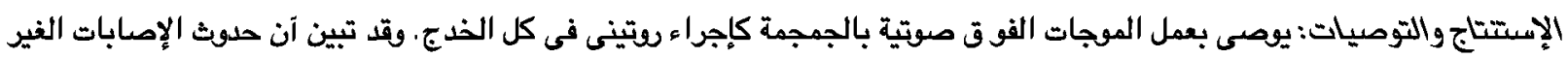

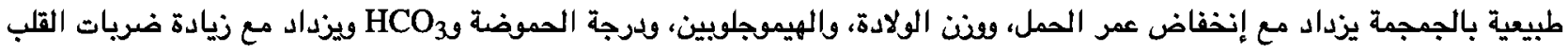

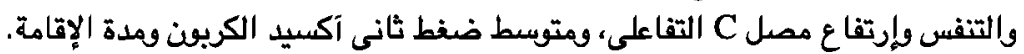

